\title{
Late effects of subarachnoid haemorrhage on the response of the primate cerebral circulation to drug-induced changes in arterial blood pressure
}

\author{
J . D. P I CK A R D, D.P. J . B O IS VER T, D. I. GRA H A M, \\ A N D W. F I T C H \\ From the Wellcome Surgical Research Institute and the University Departments of Neurosurgery, \\ Neuropathology, and Anaesthesia, University of Glasgow, Glasgow
}

SUMMARY The ability of the cerebral circulation to maintain a constant level of cerebral blood flow with halothane-induced hypotension and angiotensin-induced hypertension was found to be impaired one week after subarachnoid haemorrhage in the baboon. No evidence of hypoxic brain damage was found. The clinical significance of these findings is discussed.

Of the hypotheses which have been advanced to explain the deterioration in neurological function associated with subarachnoid haemorrhage, two are worthy of consideration. In the first place it has been suggested that intravascular platelet aggregation may occur within the cerebral arteries with embolisation of platelet thrombi and subsequent infarction (Symon, 1967). Secondly, an alteration in the normal reactivity of the cerebral vessels may take place as a result of the presence of blood in the subarachnoid space. This may make the brain less tolerant to changes in blood gases, intracranial pressure, and blood pressure (Symon, 1978). Ethically, neither of these hypotheses can be tested rigorously in clinical practice. In the present report we present data obtained in an animal model which relate to the second of these hypotheses, with particular reference to the more delayed effects of subarachnoid haemorrhage on the ability of the brain to maintain a constant level of cerebral blood flow in the face of changing cerebral perfusion pressure.

An abstract of our findings has been presented to the British Anaesthetic Research Society (Fitch et al., 1978).

\section{Methods}

The detailed methodology of this study has been presented in the preceding paper (Boisvert et al.,

Address for reprint requests: Dr William Fitch, University Department of Anaesthesia, Glasgow Royal Infirmary, Castle Street, Glasgow, G4 OSF, Scotland.

Accepted 4 April 1979
1979), and thus methods will be given only in summary here.

Initially, 13 young adult baboons were anaesthetised with thiopentone and halothane in $70 \%$ nitrous oxide and oxygen. Endotracheal intubation was performed and ventilation was controlled. The suprachiasmatic cistern was punctured with a needle passed percutaneously through the optic foramen without enucleation of the orbit. Once a free flow of cerebrospinal fluid had been obtained, $0.75 \mathrm{ml} / \mathrm{kg}$ of the animal's own arterial blood was injected into the subarachnoid space over 30 seconds. After the production of the artificial subarachnoid haemorrhage anaesthesia was discontinued and the animals were returned to their cages.

One week later, the animals were reanaesthetised-on these occasions, phencyclidine was used as the supplement to nitrous oxide in place of halothane. After the determination of baseline values, mean arterial pressure was decreased progressively in six animals by the administration of increasing concentrations of halothane. Cerebral blood flow was determined at each step decrease in systemic arterial pressure by external scintillation counting over the right parietal area after the intracarotid injection of xenon-133. In 11 baboons the effect of an acute increase in mean arterial pressure produced by an intravenous infusion of angiotensin (Hypertensin, Ciba) into the range $110-130 \mathrm{mmHg}(14.6-17.3 \mathrm{kPa})$ was studied. From our previous studies in this species, this increase in blood pressure does not exceed the upper limit of autoregulation in normal baboons (see Discus- 
sion). At the conclusion of each investigation 12 of the 13 animals were perfusion-fixed and a complete neuropathological examination was undertaken. In four animals the effects of both hypotension and hypertension were studied. In these animals the increase in arterial pressure was produced initially, and the decrease in arterial pressure was produced subsequent to a return to baseline values.

\section{Results}

Baseline values obtained before any change was made in the systemic arterial pressure were comparable in both groups studied (Table), and were similar to values obtained for these indices in previous studies which had used the same method for the determination of cerebral blood flow (CBF) and were undertaken using similar techniques of anaesthesia (Harper et al., 1972; Strandgaard et al., 1974; Fitch et al., 1976).

Table Baseline values of baboons one week after subarachnoid haemorrhage (mean $\pm S D$ )

\begin{tabular}{|c|c|c|}
\hline & $\begin{array}{l}\text { Induced } \\
\text { hypertension } \\
(N=11)\end{array}$ & $\begin{array}{l}\text { Induced } \\
\text { hypotension } \\
(N=6)\end{array}$ \\
\hline Mean arterial pressure $(\mathrm{mmHg})$ & $96 \pm 13$ & $95 \pm 23$ \\
\hline Cerebral blood flow (m1/100g.min ${ }^{-1}$ ) & $46 \pm 11$ & $51 \pm 19$ \\
\hline Cerebrovascular resistance (units) & $1.95 \pm 0.58$ & $1.84 \pm 0.61$ \\
\hline $\begin{array}{l}\text { Cerebral metabolic rate } \\
\left(\mathrm{ml} \mathrm{O}_{2} / 100 \mathrm{~g} \cdot \mathrm{min}^{-1}\right)\end{array}$ & $3.19 \pm 0.56$ & $3.24 \pm 0.89$ \\
\hline $\begin{array}{l}\text { Arterial carbon dioxide tension } \\
(\mathrm{mmHg})\end{array}$ & $39.4 \pm 1.4$ & $40.0 \pm 2.2$ \\
\hline
\end{tabular}

\section{INDUCED HYPERTENSION}

In this group of animals baseline values for mean CBF ranged from 32 to $65 \mathrm{ml} / 100 \mathrm{~g}$. min $^{-1}$ (mean $\pm \mathrm{SD}=46.2 \mathrm{ml} / 100$ g. $\mathrm{min}^{-1} \pm 10.6$ ) at a mean $\mathrm{PaCO}_{2}$ of $39.4 \mathrm{mmHg}(5.24 \mathrm{kPa})$. Baseline mean arterial pressures varied between 74 and 116 $\mathrm{mmHg}$ (mean $\pm \mathrm{SD}=96 \mathrm{mmHg} \pm 13$ ).

After the intravenous infusion of angiotensin there was, in each animal, an increase in mean arterial pressure to a new mean $( \pm \mathrm{SD})$ value of $126 \mathrm{mmHg}( \pm 13.5)$ and, in association with this alteration in arterial pressure, there was a significant $(P=0.01)$ increase in $C B F$ to a new mean ( \pm SD) value of $59.3 \mathrm{ml} / 100 \mathrm{~g} . \min ^{-1}( \pm 21.0)$ (Figure). There was no significant change in mean arterial carbon dioxide tension between the baseline value and the value obtained in association with the increased systemic arterial pressure.

\section{INDUCED HYPOTENSION}

Before the induction of hypotension in these animals, mean arterial pressure ranged from 62 to $125 \mathrm{mmHg}$ (mean $\pm \mathrm{SD}=95 \pm 23 \mathrm{mmHg}$ ) and the baseline values for mean CBF varied between 32 and $79 \mathrm{ml} / 100 \mathrm{~g} . \mathrm{min}^{-1}($ mean $\pm \mathrm{SD}=51.0 \pm 19.1)$ at normal carbon dioxide tensions.

As the mean arterial pressure was lowered progressively by the administration of increasing concentrations of halothane, mean CBF was observed to decrease progressively in each animal (Figure), so that there appeared to be a linear or almost linear relationship between mean arterial pressure and $\mathrm{CBF}$. The lowest $\mathrm{CBF}$ reached ranged from 20 to $40 \mathrm{ml} / 100 \mathrm{~g} / \mathrm{min}$, the mean being $28 \pm 7 \mathrm{SD}$.

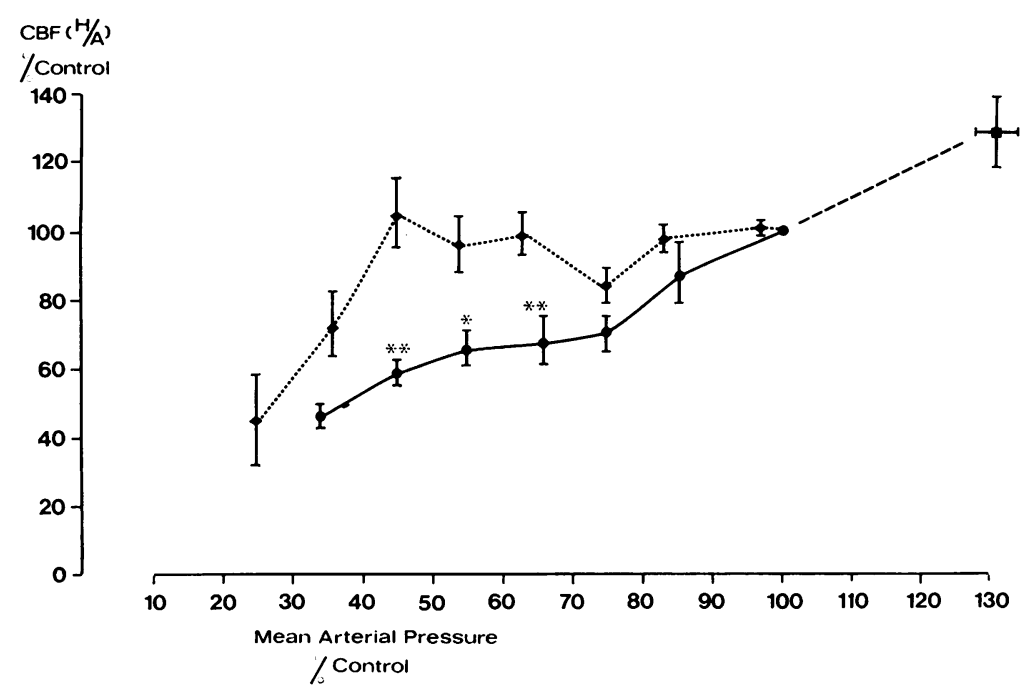

Figure Effect of changes in arterial pressure on cerebral blood flow (mean $\pm S E$ ) in normotensive control baboons $(\bullet-.-\bullet$ data from Fitch et al., 1976) and one week after subarachnoid haemorrhage $(\bullet-\bullet ;)$. Hypotension was induced with halothane $(\bullet . . . \bullet ; \bullet-\bullet)$ and hypertension with angiotensin (घ). ${ }^{*} P<0.05 ;{ }^{* *} P<0.01$. 


\section{NEUROPATHOLOGY}

\section{Macroscopic}

As judged by the uniform blanching and hardness of the specimens, fixation was thought to have been adequate in all animals. There was no evidence of internal herniation.

\section{Microscopic}

The cytological artefacts-the "dark cell" and "hydropic cell"-were minimal (Cammermeyer, 1961; Brierley et al., 1971). The only microscopic feature of note was a solitary small focus of hypoxic damage in the cortex of the posterior temporal region of one animal. The appearances were those of ischaemic cell change with and without incrustation, as described previously for material fixed in $\mathbf{4 0} \%$ formaldehyde; glacial acetic acid; absolute methanol, 1:1:8 (Brown and Brierley, 1968; Brierley et al., 1971). None of the histological features of raised intracranial pressure were seen (Adams and Graham, 1976). There was, however, a mild infiltration of the meninges by polymorphonuclear leucocytes and monocytes. Some residual blood was seen in the subarachnoid space and small amounts of haemosiderin were seen in phagocytes. The arachnoid granulations were unremarkable in the animals examined.

\section{Discussion}

The main conclusion of this paper is that autoregulation of cerebral blood flow to angiotensininduced hypertension and halothane-induced hypotension is impaired one week after subarachnoid haemorrhage. These animals would clinically be classified as grade 1 and, therefore, neurological impairment is not necessarily present when autoregulation is impaired.

\section{SYSTEMIC HYPOTENSION}

In normal man and animals, CBF remains relatively unchanged until the mean arterial pressure has decreased to $55-65 \%$ of baseline with haemorrhage and to $35-40 \%$ of baseline with halothane (Lassen, 1959; Fitch et al., 1976). By contrast, in the present study, CBF decreased progressively as mean arterial pressure was reduced by halothane.

\section{ACUTE HYPERTENSION}

In the normal, normotensive animal, CBF is unaffected by moderate increases in arterial pressure. However, there is an upper limit to this ability (130-140 $\mathrm{mmHg}$ ) such that, when exceeded, "breakthrough of autoregulation" occurs and CBF increases (Lassen and Agnoli, 1973; Strand- gaard et al., 1974). In this study, CBF increased with increasing arterial pressure: the rise in the latter was kept below the proven upper limit of autoregulation for this species (Strandgaard et al., 1974). Any agent used to test autoregulation should have no effect per se on cerebral blood vessels. Angiotensin, once it penetrates the bloodbrain barrier, constricts pial arterioles but has little effect on CBF overall in the normal baboon (Acar and Pickard, 1978; Pickard et al., 1977). Clearly, the increase in CBF with hypertension in this series cannot be explained by a cerebral vasoconstrictor action of angiotensin.

The pial arteriolar sympathetic nerve endings are depleted of their catecholamine stores after subarachnoid haemorrhage (Frazer et al., 1970; Peerless and Kendall, 1974; Svengaard et al., 1977). However, impaired autoregulation cannot be the result of this depletion: sympathectomy changes the position of upper and lower limits of autoregulation but not the basic ability to autoregulate per se (Fitch et al., 1975).

\section{PREVIOUS EXPERIMENTAL STUDIES}

Impairment of autoregulation has been noted previously but always in the acute phase after subarachnoid haemorrhage when changes in CSF acid-base balance and intracranial pressure complicate interpretation of the findings (Hashi et al., 1972; Fein and Boulos, 1973; Fein, 1976; Boisvert et al., 1978). In addition, the possibility of an upper limit to autoregulation in the normal animal was not appreciated at the time of the earlier studies. Clinically, it is the protracted impairment of autoregulation after subarachnoid haemorrhage which is the important factor to be considered rather than the acute changes after subarachnoid haemorrhage.

\section{CLINICAL STUDIES}

Heilbrun et al. (1972) found evidence of focal vasoparalysis and, on occasions, of global impairment of autoregulation in patients with subarachnoid haemorrhage before surgery. Using an electromagnetic flow probe on the internal carotid artery or one of its main intracranial branches, Nornes et al. (1977) determined the lower limit of autoregulation to trimetaphan-induced hypotension in patients with subarachnoid haemorrhage who were in grades 1 to 3 of the Hunt-Hess classification. They found that the mean arterial pressure at which the flow in the internal carotid artery began to decrease was shifted upwards by approximately $14 \mathrm{mmHg}$ in the patients in grade 3 when compared with those in grades 1 and 2 . Griffiths et al. (1974) induced systemic hypo- 
tension, using sodium nitroprusside, in patients with subarachnoid haemorrhage and found no overall impairment of autoregulation. However, of 20 patients studied, nine showed considerable decreases in cerebral blood flow once the mean arterial pressure had been decreased. In 10 patients where halothane was used to produce hypotension during aneurysm surgery after subarachnoid haemorrhage, four patients had defective autoregulation (Pickard et al., unpublished observations).

Induced hypertension has been suggested to be of value in patients with neurological deficits associated with subarachnoid haemorrhage and vasospasm (Kosnik and Hunt, 1976; Symon, 1978). The risk of the development of cerebral oedema if autoregulation is impaired has not been adequately assessed.

\section{NEUROPATHOLOGY}

In the six animals subjected to halothane-induced hypotension, there was no evidence of hypoxic damage either in the arterial boundary zones or in areas reflecting patterns of selective vulnerability to a major decrease in cerebral perfusion pressure (Adams et al., 1966; Brierley, 1976; Graham, 1977). This absence of hypoxic damage indicates that even though the animals had lost the ability to autoregulate, CBF had not fallen below the level thought to be critical for the production of brain damage in normotensive animals (Symon, 1978). It is the combination of impaired autoregulation with a second insult such as a haematoma, raised intracranial pressure, hypotension, or hypoxia which may precipitate infarction.

There is a high incidence of infarction in the brains of patients after subarachnoid haemorrhage (Tomlinson, 1959; Crompton, 1964a, b) but its pathogenesis is not known. It is probably multifactorial but, if an analogy is made with ischaemic brain damage found in the brains of patients dying from nonmissile head injury, significant factors may include vasospasm and intracranial haematoma (Macpherson and Graham, 1978), and an episode of hypoxia and raised intracranial pressure (Graham et al., 1978). To our knowledge such a detailed analysis has not been undertaken either in man or in the experimental animal. Although cerebral infarction has been described in nine of 18 monkeys after repeated subarachnoid haemorrhage (Weir et al., 1970), the description of the neuropathological findings leaves room for doubt. The animals were not perfusion-fixed-some died during the experiment or in the immediate postoperative period-and the microscopic appearances of the ischaemic areas were neither sufficiently detailed nor illustrated to allow an assessment of their approximate duration or separation from the cytological artefacts "the dark cell" and "hydropic cell” (Cammermeyer, 1961; Brierley et al., 1971). The pathophysiology of ischaemic brain damage after subarachnoid haemorrhage has, therefore, not yet been defined, but from the present study it would seem likely that at least one factor is an altered reactivity of the cerebral circulation in response to changes in the mean arterial blood pressure. The basis of this altered reactivity may be ultrastructural damage to the intracranial arteries (Boisvert et al., 1979).

We are grateful to the nursing and technical staff of the Wellcome Surgical Research Institute, University of Glasgow, for their skilled assistance and to Mrs W. McDermid and Mrs R. Burgess for their care with the manuscript. The work was supported by funds from the Medical Research Council. D. P. J. Boisvert was in receipt of a Medical Research Council (Canada) Research Fellowship.

\section{References}

Acar, U., and Pickard, J. D. (1978). Effect of angiotensin II on pial arterioles. Journal of Physiology, 284, 58-59P.

Adams, J. H., Brierley, J. B., Connor, R. C. R., and Treip, C. S. (1966). The effects of systemic hypotension upon the human brain. Clinical and neuropathological observations in 11 cases. Brain, 89, 235-268.

Adams, J. H., and Graham, D. I. (1976). The relationship between ventricular fluid pressure and the neuropathology of raised intracranial pressure. Neuropathology and Applied Neurobiology, 2, 323332.

Boisvert, D. P., Overton, T. R., Weir, B., and Grace, M. G. (1978). Cerebral arterial responses to induced hypertension following subarachnoid hemorrhage in the monkey. Journal of Neurosurgery, 49, 7583.

Boisvert, D. P. J., Pickard, J. D., Graham, D. I., and Fitch, W. (1979). Delayed effects of subarachnoid haemorrhage on cerebral metabolism and the cerebrovascular response to hypercapnia in the primate. Journal of Neurology, Neurosurgery, and Psychiatry, 42, 892-898.

Brierley, J. B., Brown, A. W., and Meldrum, B. S. (1971). The nature and time course of the neuronal alterations resulting from oligaemia and hypoglycaemia in the brain of Macaca mulatta. Brain Research, 25, 483-499.

Brierley, J. B. (1976). Cerebral hypoxia. In Greenfield's Neuropathology, pp. 43-85. Edited by W. Blackwood and J. A. N. Corsellis. Edward Arnold: London. 
Brown, A. W., and Brierley, J. B. (1968). The nature, distribution and earliest stages of anoxic-ischaemic nerve cell damage in the rat brain as defined by the optical microscope. British Journal of Experimental Pathology, 49, 87-106.

Cammermeyer, J. (1961). The importance of avoiding "dark" neurons in experimental neuropathology. Acta Neuropathology (Berlin), 1, 245-270.

Crompton, M. R. (1964a). Cerebral infarction following the rupture of cerebral berry aneurysms. Brain, 87, 263-280.

Crompton, M. R. (1964b). The pathogenesis of cerebral infarction following the rupture of cerebral berry aneurysms. Brain, 87, 491-510.

Fein, J. M. (1976). Brain energetics and circulatory control after subarachnoid hemorrhage. Journal of Neurosurgery, 45, 498-507.

Fein, J. M., and Boulos, R. (1973). Local cerebral blood flow in middle cerebral artery vasospasm. Journal of Neurosurgery, 39, 337-347.

Fitch, W., MacKenzie, E. T., and Harper, A. M. (1975). Effects of decreasing arterial pressure on cerebral blood flow: influence of the sympathetic nervous system. Circulation Research, 37, 550-557.

Fitch, W., Ferguson, C. G., Sengupta, D., Garibi, J., and Harper, A. M. (1976). Autoregulation of cerebral blood flow during controlled hypotension in baboons. Journal of Neurology, Neurosurgery, and Psychiatry, 39, 1014-1022.

Fitch, W., Pickard, J. D., Boisvert, D. P. J., and Graham, D. I. (1978). Effect of recent subarachnoid haemorrhage on the reactivity of the cerebral circulation. British Journal of Anaesthesia, 50, 1086P.

Frazer, R. A. R., Stein, B. M., Barrett, R. E., and Pool, J. L. (1970). Noradrenergic mediation of experimental cerebrovascular spasm. Stroke, 1, 356362.

Graham, D. I. (1977). Pathology of hypoxic brain damage in man. Journal of Clinical Pathology, 11, $170-180$.

Graham, D. I., Adams, J. H., and Doyle, D. (1978). Ischaemic brain damage in fatal non-missile head injuries. Journal of the Neurological Sciences, 39 , 213-234.

Griffiths, D. P. G., Cummins, B. H., Greenbaum, R., Griffith, H. B., Staddon, G. E., Wilkins, D. G. and Zorab, J. S. M. (1974). Cerebral blood flow and metabolism during hypotension induced with sodium nitroprusside. British Journal of Anaesthesia, 46, 671-679.

Harper, A. M., Deshmukh, V. D., Rowan, J. O., and Jennett, W. B. (1972). Influence of sympathetic nervous activity on cerebral blood flow. Archives of Neurology (Chicago), 27, 1-6.

Hashi, K., Meyer, J. S., Shinmaru, S., Welch, K. M. A., and Teraura, T. (1972). Changes in cerebral vasomotor reactivity to $\mathrm{CO}_{2}$ and autoregulation following experimental subarachnoid haemorrhage. Journal of the Neurological Sciences, 17, 15-22.
Heilbrun, M. P., Olesen, J., and Lassen, N. A. (1972). Regional cerebral blood flow studied in subarachnoid hemorrhage. Journal of Neurosurgery, 37, 36-44.

Kosnik, E. J., and Hunt, W. E. (1976). Postoperative hypertension in the management of patients with intracranial arterial aneurysms. Journal of Neurosurgery, 45, 148-154.

Lassen, N. A. (1959). Cerebral blood flow and oxygen consumption in man. Physiological Review, 39, 183-238.

Lassen, N. A., and Agnoli, A. (1973). Upper limit of autoregulation of cerebral blood flow in the pathogenesis of acute hypertensive encephalopathy. Scandinavian Journal of Clinical and Laboratory Investigation, 30, 113-116.

Macpherson, P., and Graham, D. I. (1978). Correlation between angiographic findings and the incidence of head injury. Journal of Neurology, Neurosurgery, and Psychiatry, 41, 122-127.

Nornes, H., Knutzen, H. B., and Wilkeby, P. (1977). Cerebral arterial blood flow and aneurysm surgery. 2 . Induced hypotension and autoregulatory capacity. Journal of Neurosurgery, 47, 819-827.

Peerless, S. J., and Kendall, M. J. (1974). Experimental cerebral vasospasm. In Proceedings of the Ninth Princeton Conference on Cerebral Vascular Disease, pp. 49-58. Edited by J. P. Whisnant and B. A. Sandok. Grune and Stratton: New York.

Pickard, J. D., Durity, F., Welsh, F. A., Langfitt, T. W., Harper, A. M., and MacKenzie, E. T. (1977). Osmotic opening of the blood brain barrier: value in pharmacological studies on the cerebral circulation. Brain Research, 122, 170-176.

Strandgaard, S., MacKenzie, E. T., Sengupta, D., Rowan, J. O., Lassen, N. A., and Harper, A. M. (1974). Upper limit of autoregulation of cerebral blood flow in the baboon. Circulation Research, 34, 435-440.

Svengaard, N. A., Edvinsson, L., and Owman, C. (1977). Changes in sensitivity of cerebral vessels to noradrenaline and 5-hydroxytryptamine in the presence of subarachnoid blood. Acta Neurologica Scandinavica, 56, Supplement 64, 318-319.

Symon, L. (1967). Vascular spasm in the cerebral circulation. In Background to Migraine-First Migraine Symposium, pp. 78-95. William Heinemann: London.

Symon, L. (1978). Disordered cerebrovascular physiology in aneurysmal subarachnoid haemorrhage. Acta Neurochirurgica, 41, 7-22.

Tomlinson, B. E. (1959). Brain changes in ruptured intracranial aneurysm. Journal of Clinical Pathology, 12, 391-399.

Weir, B., Erasmo, R., Miller, J., McIntyre, J., Secord, D., and Miekle, B. (1970). Vasospasm in response to repeated subarachnoid hemorrhages in the monkey. Journal of Neurosurgery, 33, 395406. 